\title{
Stefan Baumgärtner, Malte Faber and Johannes Schiller: Joint Production and Responsibility in Ecological Economics. On the Foundations of Environmental Policy
}

\author{
Edward Elgar, Cheltenham, UK, Northampton, MA, USA, \\ 2006, 392 pp, ISBN-13: 978-1-84064-872-0
}

\section{Guido Buenstorf}

Published online: 27 September 2007

(C) Springer-Verlag 2007

Evolutionary and ecological economics share a similar history. Discontent with standard economics was a major impetus in the emergence of both fields. In the case of ecological economics, understanding and overcoming the limits of standard economic tools in addressing environmental issues was most important. Both fields are moreover characterized by methodological plurality, including an openness to draw on concepts and findings imported from other disciplines. Neither has developed a canonical approach, but the diversity in methods has been sustained. Evolutionary and ecological economics also share common interests. Most notably, both are concerned with long-term development, and with the interrelations between the natural and the socio-economic spheres. These parallels make it worthwhile for evolutionary economists to keep track of advances and discussions in ecological economics.

For more than 20 years, Malte Faber, professor emeritus at the University of Heidelberg, has been a leading theorist of ecological economics. In contrast to many other ecological economists (but not unlike Nicholas Georgescu-Roegen, the towering pioneer of that field), Faber came from economic theory, specifically Austrian capital theory, and he has always maintained a close relationship to it. At the same time, he has engaged in interdisciplinary research of an unusual scope. His collaborators and students include researchers trained in physics, chemistry, and engineering, as well as philosophy and management. Based on their diverse backgrounds, Faber and his collaborators have integrated ideas from disciplines as dissimilar as thermodynamics and ethics into theoretical advances that are solidly grounded in economics and build on accepted economic concepts. The result is a

G. Buenstorf $(\bowtie)$

Max Planck Institute of Economics, Evolutionary Economics Group, Kahlaische Strasse 10,

07745 Jena, Germany

e-mail: buenstorf@econ.mpg.de 
highly original contribution to economics. Even though this work primarily addresses the conceptual foundations of ecological economics, it holds the potential to be generalized beyond environmental applications.

The present volume brings together two major lines of the Faber group's recent research, mostly building on previously published material (some of which has not been available in English before). Joint production-the necessary emergence of multiple outputs from a production process - is adopted as the integrating concept of the analysis; it is linked both to the physical level of thermodynamics and to the normative level of moral philosophy. The volume is co-authored with two of Faber's former students, who have since successfully pursued their own research agendas: Stefan Baumgärtner, professor of sustainability economics at the University of Lüneburg, and Johannes Schiller, now at the Helmholtz Center for Environmental Research in Leipzig. Beyond these three authors, eight additional individuals are credited as substantial contributors to the overall argument or individual chapters.

Joint Production and Responsibility in Ecological Economics consists of 19 chapters organized into four parts. The first part lays out the conceptual foundations of joint production. Four aspects are noteworthy. First, joint production is understood as a contingent phenomenon. Its presence is dependent on the chosen system representation as well as the time horizon of the analysis. For a physical representation of production based on the laws of thermodynamics, the authors show that all production necessarily results in joint products. Second, a broad notion of joint production is adopted. In addition to the interest in environmentally harmful joint products that motivates the analysis, the concept is also advocated to deal with non-quantifiable joint outputs such as knowledge from learning-by-doing or preference change resulting from consumption experience. Third, joint production is treated as a dynamic phenomenon, as production processes may result in outputs at different points in time, giving rise to inevitable intertemporal links. Threshold effects and the accumulation of stocks of joint products may, moreover, cause longterm problems that are not visible in a short-run analysis. Finally, the authors emphasize the ambivalence of joint products: whether or not joint products have a positive value is not given a priori but depends on agents' valuations, which may be fundamentally altered by changes in technology or preferences. Thus, adopting the concept of joint production allows for the study of environmental problems at a more fundamental level than do standard welfare economic approaches.

The second part-titled "Economics" - uses the history of thought as its point of departure. It is shown how problems of accounting for joint production were instrumental in the abandonment of the objective classical value theory. Neoclassical general equilibrium theory was likewise unable to develop a general theory of joint production, but adopted simplifying assumptions such as non-negative output prices or free disposal that excluded puzzling (but relevant) cases of joint production. While the external effects of unwanted outputs became a topic for welfare economics, no theory of ambivalent joint products was developed. One chapter of Joint Production and Responsibility in Ecological Economics is exclusively devoted to this issue, and to factors that may turn unwanted outputs into positively valued ones (or vice versa). Drawing on capital theory and interpreting stocks of pollutants as "capital bads," the authors also discuss investment decisions in the presence of unwanted outputs. 
Part Three turns to the normative issues raised by joint production. The key concept suggested in this context is responsibility, and the discussion is primarily based on contributions from the history of moral philosophy. Through the nexus of joint products and limited knowledge, the responsibility concept is linked to the earlier parts of the volume. To what extent, then, do producers have to assume responsibility for the outputs of their activities? Producers cannot reject, the authors argue, their responsibility for ambivalent joint products with ex ante unknown desirability. Accordingly, a traditional criterion of individual responsibility traced back to Hegel is found unsuitable to deal with ambivalent joint production. As an alternative, a modified criterion is put forward. It stresses the individual's duty to acquire knowledge about potential joint outputs, while remaining aware that one's knowledge is limited. An even more encompassing responsibility is assigned to policy makers, who need both to restrict their own actions and to set legal standards limiting the actions of other agents such that uncontrollable consequences are prevented.

In the final part of the book, four chapters present case studies of different industries (waste paper, chlorine, cement, and sulfuric acid), each highlighting one specific aspect of joint production. All case studies assume a long-term perspective and show how the evolution of industries was affected by joint products. Innovative attempts to deal with unwanted joint products triggered the development of entirely new lines of production using them as crucial inputs, which illustrates the significance of ambivalent joint production. It is also shown that joint products may give rise to complex interdependencies among otherwise unrelated industries.

With its fundamentally dynamic perspective and the emphasis on the dynamics of resource stocks as a cause of time lags, system inertia, and endogenous change, the approach of Joint Production and Responsibility in Ecological Economics is congenial to evolutionary thinking. Limits of predictability in economics, and the ensuing normative issues, are taken seriously. Many of the issues raised in the volume are relevant beyond environmental economics, notably in the context of innovation and industry evolution. At the same time, the conclusions from the analysis remain at a rather abstract conceptual level. In spite of the authors' interest in environmental policy, no specific recommendations for concrete policy measures are developed.

Given the breadth of argument and the number of collaborators, it is perhaps no surprise that the volume is not monolithic in its style of argument. Indeed, the reader needs to bring some willingness to adapt to changing modes of reasoning, ranging from physical and economic models to historical and philosophical arguments. The volume is nonetheless far more unified than a collection of loosely related essays, and makes for a valuable read in its entirety. To readers unfamiliar with the Faber group's earlier work, it offers an accessible introduction to the group's key ideas. Those who know the previous books will nonetheless find the present volume interesting, as it contains numerous further advances and generalizations, as well as an integration of ideas that have not been presented in a unified form before.

From an evolutionary perspective, the most critical point is the limited consideration of the evolutionary literature. Joint Production and Responsibility in Ecological Economics contains much that is attractive for evolutionary research. It touches on issues such as genuine uncertainty and ignorance, or the endogenous 
emergence of innovations, which lie at the heart of evolutionary economics. However, the prior evolutionary work is largely eclipsed. This is in stark contrast to the thorough consideration given to mainstream economics and other heterodox strands of research such as the Sraffian tradition. It also differs from the group's earlier work (cf. e.g., Faber et al. 1996; Faber and Proops 1998).

The volume thus invites further discourse between evolutionary and ecological economists. For evolutionary economists, it is a highly commendable introduction into an important strand of ecological economics, and also an outside source of inspiration that may be beneficial for their own research. In turn, ecological researchers might benefit from adopting evolutionary concepts such as frequency dependence and critical masses, and from complementing the normative thinking of moral philosophy with behavioral findings on human nature.

\section{References}

Faber M, Proops J (1998) Evolution, time, production and the environment, 3rd edn. Springer, Berlin Heidelberg New York

Faber M, Manstetten R, Proops J (1996) Ecological economics: concepts and methods. Cheltenham UK and Brookfield, VT, USA 